\section{(C) OPEN ACCESS}

\title{
Prophylactic effect of trimethoprim-sulfamethoxazole for pneumocystis pneumonia in patients with rheumatic diseases exposed to prolonged high-dose glucocorticoids
}

\author{
Jun Won Park, ${ }^{1}$ Jeffrey R Curtis, ${ }^{2}$ Jinyoung Moon, ${ }^{1}$ Yeong Wook Song, ${ }^{1}$ \\ Suhnggwon Kim, ${ }^{3,4}$ Eun Bong Lee ${ }^{1}$
}

Handling editor Tore K Kvien

- Additional material is published online only. To view please visit the journal online (http://dx.doi.org/10.1136/ annrheumdis-2017-211796).

${ }^{1}$ Division of Rheumatology, Department of Internal Medicine, Seoul National University College of Medicine, Seoul, Republic of Korea ${ }^{2}$ Division of Clinical Immunology and Rheumatology, University of Alabama at Birmingham, Birmingham, Alabama, USA ${ }^{3}$ Division of Nephrology, Department of Internal University College of Medicine, Seoul, Republic of Korea ${ }^{4}$ Seoul Kidney Clinic, Seoul, Republic of Korea

\section{Correspondence to}

Dr Eun Bong Lee, Division of Rheumatology, Department of Internal Medicine, Seoul National University College of Medicine, Seoul 110-744, Republic of Korea; leb7616@snu.ac.kr

Received 15 May 2017 Revised 1 October 2017 Accepted 22 October 2017

Published Online First

1 November 2017 Medicine, Seoul National

\section{ABSTRACT \\ Objectives To investigate the efficacy and safety of trimethoprim/sulfamethoxazole (TMP-SMX) as primary prophylaxis for pneumocystis pneumonia (PCP) in patients with rheumatic diseases receiving high-dose steroids.}

Methods The study included 1522 treatment episodes with prolonged ( $\geq 4$ weeks) high-dose ( $\geq 30 \mathrm{mg} /$ day prednisone) steroids in 1092 patients over a 12-year period. Of these, 262 treatment episodes involved TMPSMX (prophylaxis group) while other episodes involved no prophylaxis (control group). Differences in 1-year PCP incidence and its mortality between the two groups were estimated using Cox regression. To minimise baseline imbalance, propensity score matching was performed and efficacy outcome was mainly assessed in the postmatched population ( $n=235$ in both groups).

Results During a total of 1474.4 person-years, 30 PCP cases occurred with a mortality rate of $36.7 \%$. One nonfatal case occurred in the prophylaxis group. TMP-SMX significantly reduced the 1-year PCP incidence (adjusted $\mathrm{HR}=0.07(95 \% \mathrm{Cl} 0.01$ to 0.53$))$ and related mortality (adjusted $\mathrm{HR}=0.08(95 \% \mathrm{Cl} 0.0006$ to 0.71$))$ in the postmatched population. The result of the same analysis performed in the whole population was consistent with that of the primary analysis. Incidence rate of adverse drug reactions (ADR) related to TMP-SMX was 21.2 (14.8-29.3)/100 person-years. Only two serious ADRs (including one Stevens-Johnson syndrome case) occurred. The number needed to treat for preventing one PCP (52 (33-124)) was lower than the number needed to harm

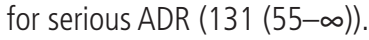

Conclusion TMP-SMX prophylaxis significantly reduces the PCP incidence with a favourable safety profile in patients with rheumatic disease receiving prolonged, high-dose steroids.

\section{INTRODUCTION}

Linked

http://dx.doi.org/10.1136/ annrheumdis-2017-212588

Check for updates

To cite: Park JW, Curtis JR, Moon J, et al. Ann Rheum Dis 2018;77:644-649.
Pneumocystis pneumonia (PCP) caused by Pneumocystis jirovecii is a common but potentially life-threatening infection in immunocompromised cause of death in patients infected by HIV, the advent of effective HIV treatment and prophylactic strategy led to marked fall of its incidence. ${ }^{2}$ However, it remains a significant cause of pneumonia in non-HIV immunocompromised patients. In addition, PCP in non-HIV patients usually shows patients. ${ }^{1}$ Although it had been the most common more severe manifestations and carries a higher mortality rate than that in $\mathrm{HIV}$-infected patients. ${ }^{3-5}$

The most important risk factor for PCP in non-HIV patients is the use of immunosuppressive drugs, especially corticosteroids. Prolonged treatment with high-dose steroids is a significant risk factor for PCP in patients with haematologic malignancies, solid organ transplants and rheumatic diseases. ${ }^{467}$ Thus, current guidelines recommend PCP prophylaxis for patients receiving immunosuppressive drugs, including steroids. ${ }^{8}$ However, there is no consensus on PCP prophylaxis for patients with rheumatic diseases because the absolute incidence of PCP in this group is unclear ${ }^{9}$ and no risk-benefit assessment for prophylactic regimen has been performed. Thus, this has led to different opinions among rheumatologists regarding PCP prophylaxis. $^{10}$

To find the answers to these problems, we examined the incidence of PCP in patients diagnosed with a rheumatic disease and receiving prolonged high-dose steroid treatment. Patients were recruited from a large tertiary referral centre over a 12 -year period. In addition, we evaluated the efficacy and safety of PCP prophylaxis to enable a useful risk-benefit assessment.

\section{METHODS}

\section{Patients and clinical data}

The electronic medical database at Seoul National University Hospital was examined, and patients with a rheumatic disease treated with high-dose steroid for more than 4 consecutive weeks (defined as a treatment episode) between January 2004 and December 2015 were identified. High-dose steroid was defined as $\geq 30 \mathrm{mg} /$ day prednisone or equivalent, as suggested by Buttgereit et al. ${ }^{11}$ The ICD-10 (International Classification of Diseases, 10th Revision) codes used for case identification are presented in online supplementary text. Patients with a history of PCP, HIV infection, current cancer, or a solid organ transplant, or those less than 18 years of age were excluded. Next, all treatment episodes were classified into two groups (control group vs prophylaxis group) according to whether a patient receiving high-dose steroid had started primary PCP prophylaxis.

The baseline date was defined as the first day of PCP prophylaxis (prophylaxis group) or high-dose 
steroid (control group). Each patient should maintain high-dose steroid for at least 4 weeks from the baseline date. The observation period for each treatment episode was 1 year from the baseline date because previous studies suggest that most PCP cases occur within this period. ${ }^{41213}$ Therefore, prolonged highdose steroid treatment which started within the last 1 year from the baseline date in the prophylaxis group could not be entered into the observation period of the control group. But if a patient restarted prolonged high-dose steroid treatment after more than 1 year from the baseline date, it was counted as a separate treatment episode. The primary outcome was the incidence of PCP in each group during the observation. Secondary outcomes included PCP-related mortality and incidence of adverse drug reactions (ADR) related to $\mathrm{PCP}$ prophylaxis. All suspected ADRs were reviewed and assigned a probability of causation based on the timing and known patterns of adverse effects. Probable/likely or certain causality was regarded as an ADR. ${ }^{14}$

Patient consent was waived by the IRB due to the retrospective nature of the study.

\section{Detection of PCP during treatment episodes}

A complex algorithm (see online supplementary figure S1) was used to capture all PCP cases during the observation. Briefly, data from confirmatory microbiologic tests such as PCR and direct fluorescent antibody staining of induced-sputum or bronchoalveolar lavage fluid were collected. The medical records of patients with positive results and fulfilling the criteria for analysis were then reviewed to ascertain whether they showed features consistent with PCP, such as fever or acute dyspnea, along with characteristic radiographic findings. A positive PCR result in the absence of clinical manifestations was not considered as PCP.

\section{PCP prophylaxis}

Trimethoprim/sulfamethoxazole (TMP-SMX) was the only agent used for PCP prophylaxis in this study and was given as one double-strength tablet three times a week or as one singlestrength tablet per day. Selection of patients for PCP prophylaxis and its duration were mainly determined by the treating physician. TMP-SMX was started on the first day of high-dose steroid treatment in most cases (unless contraindicated) and was stopped when the daily steroid dose (based on prednisone) was tapered: to $30 \mathrm{mg}$ in $35(13.6 \%)$ treatment episodes, $25 \mathrm{mg}$ in 6 (2.3\%), $20 \mathrm{mg}$ in $26(10.1 \%), 15 \mathrm{mg}$ in $53(20.6 \%)$ and $<15 \mathrm{mg} /$ day in $113(44.0 \%)$. For patients with renal insufficiency, the TMP-SMX dose was adjusted accordingly (determined by creatinine clearance, $n=23$ ). Second-line antibiotics against PCP such as dapsone, atovaquone or aerosolised pentamidine were not used for primary prophylaxis against PCP during the observation period.

\section{Statistical analysis}

Continuous or dichotomous baseline data were compared using Student's t-test or the $\chi^{2}$ test as appropriate. Cox proportional hazards regression models were used to estimate the effect of TMP-SMX on outcome. The HR was adjusted for baseline clinical factors that showed a significant association $(\mathrm{P}<0.1)$ with outcome. In addition, the final model was adjusted for intracluster correlation as some patients may have undergone multiple treatment episodes. With respect to PCP-related mortality, which showed the complete separation of outcome, Firth's penalised maximum likelihood was used to reduce statistical bias. ${ }^{15}$

Since there were differences between the groups in terms of baseline characteristics, the same survival analyses were undertaken after applying 1:1 propensity score (PS) matching. This was carried out using the patients' age, cumulative steroid dose during the 6 months prior to baseline, concomitant use of immunosuppressants (cyclophosphamide and steroid pulse), lymphopenia $(<800 / \mu \mathrm{L})$ and the presence of certain underlying diseases as predictors of a requirement for prophylaxis; the selected calliper was 0.2 . After matching, 235 treatment episodes from each group were selected for use as the postmatched populations (see online supplementary figure S2). Although a comparison of PCP incidence and related mortality was performed before and after matching, primary outcome was mainly assessed in the postmatched population because it was expected to have less statistical bias regarding the number of covariates per case. All statistical analyses were performed using R V.3.3.1 software, and a $\mathrm{P}$ value $<0.05$ was considered statistically significant.

\section{RESULTS}

\section{Patient characteristics}

A total of 1522 treatment episodes from 1092 patients were fulfilled the criteria for analysis. TMP-SMX prophylaxis was performed in 262 treatment episodes, with a mean (SD) duration of 237.0 (272.2) days. Patients received daily single-strength TMP-SMX regimen in most treatment episodes (251/262, 95.8\%). Prophylaxis began on the first day of high-dose steroid treatment (except in nine cases in which TMP-SMX prophylaxis was delayed by more than 1 month from the initiation of highdose steroid due to acute kidney injury $(n=4)$, leucopenia $(n=3)$ or pregnancy $(\mathrm{n}=2))$.

The baseline characteristics of the control and prophylaxis groups are shown in table 1. Patients in the prophylaxis group were older, more likely to have lymphopenia and to be treated with secondary immunosuppressive agents. In addition, the proportion of patients with diseases associated with a high risk of PCP, such as granulomatosis with polyangiitis (GPA), microscopic polyangiitis (MPA) and dermatomyositis, was significantly higher in the prophylaxis group. The cumulative steroid dose administered during the entire observation period was also higher in the prophylaxis group (based on prednisone, $7158 \pm 4552 \mathrm{mg}$ vs $8202 \pm 5145 \mathrm{mg}, \mathrm{P}=0.001)$. There were no significant differences in the above-mentioned clinical factors in the postmatched population (table 2).

\section{Incidence of PCP}

During the observation period of 1474.4 person-years, there were 30 PCP cases in 30 patients: the incidence rate $(95 \% \mathrm{CI})$ in the control group was $2.37(1.59-3.41) / 100$ person-years. When the whole population was stratified according to underlying disease, the incidence of PCP was highest in those with GPA and MPA (12.14 (95\% CI 3.94 to 28.33) per 100 personyears), followed by those with systemic sclerosis (10.88 $(95 \%$ CI 2.24 to 31.80 ) per 100 person-years), dermatomyositis (3.11 (95\% CI 0.64 to 9.07) per 100 person-years) and systemic lupus erythematosus (SLE) (2.42 (95\% CI 1.36 to 4.00) per 100 person-years). The mean time interval between baseline and PCP was $3.4(\mathrm{SD}=2.5, \min =0.9, \max =10.8)$ months and $27(90.0 \%)$ cases occurred within the first 6 months. The mean (SD) dose of steroid (based on prednisone) at the time of PCP diagnosis was $31.3(\mathrm{SD}=20.1, \min =5, \max =80) \mathrm{mg} ; 15(50 \%)$ cases occurred when the dose was $\geq 30 \mathrm{mg} /$ day, 12 cases when $15-30 \mathrm{mg} /$ day and 3 cases when $<15 \mathrm{mg} /$ day. Twenty-nine cases of PCP developed in the control group, whereas only one case occurred in the prophylaxis group. However, in this case, TMP-SMX was discontinued prematurely due to ADR. Among all PCP cases, 
Table 1 Baseline* characteristics of the whole population

\begin{tabular}{|c|c|c|c|}
\hline ( $\mathrm{n}=$ number of treatment episodes) & $\begin{array}{l}\text { Control group } \\
(n=1260)\end{array}$ & $\begin{array}{l}\text { Prophylaxis } \\
\text { group } \\
(n=262)\end{array}$ & $P$ value \\
\hline Male gender, n (\%) & $374(29.7)$ & $89(34.0)$ & 0.170 \\
\hline Age, year, mean (SD) & $41.2(15.2)$ & $46.2(16.0)$ & $<0.001$ \\
\hline Disease duration, year, mean (SD) & $3.0(3.8)$ & $2.5(4.0)$ & 0.053 \\
\hline \multicolumn{4}{|l|}{ Underlying disease } \\
\hline $\begin{array}{l}\text { Systemic lupus erythematosus, } \\
\mathrm{n}(\%)\end{array}$ & $636(50.5)$ & $122(46.8)$ & 0.249 \\
\hline Systemic sclerosis, n (\%)† & $30(2.4)$ & $5(1.9)$ & 0.642 \\
\hline Dermatomyositis, n (\%) & $100(7.9)$ & $38(14.5)$ & 0.001 \\
\hline Polymyositis, n (\%) & $54(4.3)$ & $12(4.6)$ & 0.831 \\
\hline GPA, n (\%) & $38(3.0)$ & $18(6.9)$ & 0.003 \\
\hline MPA, n (\%) & $9(0.7)$ & $11(4.2)$ & $<0.001$ \\
\hline EGPA, $n(\%)$ & $43(3.4)$ & $7(2.7)$ & 0.541 \\
\hline Polyarteritis nodosa, n (\%) & $17(1.3)$ & $7(2.7)$ & 0.118 \\
\hline Rheumatoid arthritis, n (\%)† & $58(4.6)$ & $10(3.8)$ & 0.575 \\
\hline Adult-onset Still's disease, n (\%) & $31(2.5)$ & $9(3.4)$ & 0.369 \\
\hline Behcet's disease, $\mathrm{n}(\%)$ & $182(14.4)$ & $12(4.6)$ & $<0.001$ \\
\hline Cryoglobulinaemic vasculitis, n (\%) & $1(0.1)$ & $2(0.8)$ & 0.023 \\
\hline Ankylosing spondylitis, n (\%) & $12(1.0)$ & $0(0.0)$ & 0.113 \\
\hline Primary Sjogren's syndrome, n (\%) & $3(0.2)$ & $0(0.0)$ & 0.429 \\
\hline Others, $\mathrm{n}(\%) \ddagger$ & $47(3.7)$ & $9(3.4)$ & 0.817 \\
\hline $\begin{array}{l}\text { Initial steroid dose of } 30-45 \mathrm{mg} \mathrm{PD,} \\
\mathrm{n}(\%)\end{array}$ & $426(33.8)$ & $88(33.6)$ & 0.945 \\
\hline $\begin{array}{l}\text { Initial steroid dose of } 45-60 \mathrm{mg} \mathrm{PD,} \\
\mathrm{n}(\%)\end{array}$ & $141(11.2)$ & $42(16.0)$ & 0.028 \\
\hline $\begin{array}{l}\text { Initial steroid dose of } \geq 60 \mathrm{mg} \text { PD, } \mathrm{n} \\
(\%)\end{array}$ & $696(55.0)$ & $132(50.4)$ & 0.172 \\
\hline \multicolumn{4}{|c|}{ Concomitant immunosuppressive treatment } \\
\hline Steroid pulse treatment, $\mathrm{n}(\%)$ & $164(13.0)$ & $99(37.8)$ & $<0.001$ \\
\hline Oral cyclophosphamide, n (\%) & $49(3.9)$ & $34(13.0)$ & $<0.001$ \\
\hline $\begin{array}{l}\text { Cyclophosphamide pulse treatment, } \\
\mathrm{n}(\%)\end{array}$ & $99(7.9)$ & $67(25.6)$ & $<0.001$ \\
\hline Cumulative steroid dose, mean (SD)§ & $1597.1(1568.7)$ & $\begin{array}{l}3119.7 \\
(1821.5)\end{array}$ & $<0.001$ \\
\hline Lymphopenia, n (\%)ף & $283(22.5)$ & $87(33.2)$ & $<0.001$ \\
\hline \multicolumn{4}{|c|}{$\begin{array}{l}\text { *The baseline date was defined as the day on which PCP prophylaxis (prophylaxis } \\
\text { group) or high-dose steroid (control group) was started. } \\
\text { †The main reason for the use of high-dose steroids in these diseases was associated } \\
\text { interstitial lung disease. } \\
\text { fIncluding Takayasu's arteritis, temporal arteritis and relapsing polychondritis. } \\
\text { §Cumulative steroid (prednisone) dose during the previous } 6 \text { months. } \\
\text { IDefined as < } 800 \text { lymphocytes/mL. } \\
\text { EGPA, eosinophilic granulomatosis with polyangiitis; GPA, granulomatosis with } \\
\text { polyangiitis; MPA, microscopic polyangiitis; PCP, pneumocystis pneumonia; PD, } \\
\text { prednisone. }\end{array}$} \\
\hline
\end{tabular}

$16(53.3 \%)$ received mechanical ventilation and 11 (36.7\%) expired. All PCP-related deaths occurred in the control group. Clinical features of PCP cases at baseline and PCP occurrence are summarised in online supplementary tables S1 and S2, respectively.

The incidence of PCP tended to increase according to the increase in the initial steroid dose. Patients receiving $\geq 60 \mathrm{mg} /$ day prednisone showed a significantly higher PCP incidence than those in other subgroups (figure 1).

\section{Efficacy of TMP-SMX prophylaxis in the PS-matched population}

Univariable analysis in the PS-matched population revealed that the 1-year incidence of PCP significantly decreased with
Table 2 Baseline* characteristics of the PS-matched population

\begin{tabular}{|c|c|c|c|}
\hline $\begin{array}{l}\text { ( } n=\text { number of treatment } \\
\text { episodes) }\end{array}$ & $\begin{array}{l}\text { Control group } \\
(n=235)\end{array}$ & $\begin{array}{l}\text { Prophylaxis group } \\
(n=235)\end{array}$ & $P$ value \\
\hline Male gender, $\mathrm{n}(\%)$ & $173(73.6)$ & $161(68.5)$ & 0.222 \\
\hline Age, year, mean (SD) & $45.8(16.3)$ & $45.5(15.7)$ & 0.843 \\
\hline $\begin{array}{l}\text { Disease duration, year, mean } \\
\text { (SD) }\end{array}$ & $3.1(4.0)$ & $2.6(3.9)$ & 0.200 \\
\hline \multicolumn{4}{|l|}{ Underlying disease } \\
\hline $\begin{array}{l}\text { Systemic lupus } \\
\text { erythematosus, } \mathrm{n}(\%)\end{array}$ & $109(46.4)$ & $112(47.7)$ & 0.782 \\
\hline Systemic sclerosis, n (\%)† & $6(2.6)$ & $5(2.1)$ & 0.760 \\
\hline Dermatomyositis, n (\%) & $34(14.5)$ & $34(14.5)$ & 1.000 \\
\hline Polymyositis, n (\%) & $17(7.2)$ & $10(4.3)$ & 0.165 \\
\hline GPA, n (\%) & $16(6.8)$ & $13(5.5)$ & 0.565 \\
\hline MPA, n (\%) & $8(3.4)$ & $8(3.4)$ & 1.000 \\
\hline EGPA, n (\%) & $6(2.6)$ & $7(3.0)$ & 0.779 \\
\hline Polyarteritis nodosa, n (\%) & $7(3.0)$ & $6(2.6)$ & 0.779 \\
\hline $\begin{array}{l}\text { Rheumatoid arthritis, } \mathrm{n} \\
(\%) \dagger\end{array}$ & $9(3.8)$ & $9(3.8)$ & 1.000 \\
\hline $\begin{array}{l}\text { Adult-onset Still's disease, } \\
\mathrm{n}(\%)\end{array}$ & $2(0.9)$ & $8(3.4)$ & 0.106 \\
\hline Behcet's disease, n (\%) & $11(4.7)$ & $12(5.1)$ & 0.831 \\
\hline $\begin{array}{l}\text { Cryoglobulinaemic } \\
\text { vasculitis, } \mathrm{n}(\%)\end{array}$ & $1(0.4)$ & $2(0.9)$ & 0.562 \\
\hline $\begin{array}{l}\text { Ankylosing spondylitis, } \\
\mathrm{n}(\%)\end{array}$ & $3(1.3)$ & $0(0.0)$ & 0.248 \\
\hline $\begin{array}{l}\text { Primary Sjogren's } \\
\text { syndrome, } \mathrm{n}(\%)\end{array}$ & $1(0.4)$ & $0(0.0)$ & 0.317 \\
\hline Others, n (\%)‡ & $5(2.1)$ & $9(3.8)$ & 0.278 \\
\hline $\begin{array}{l}\text { Initial steroid dose of } \\
30-45 \mathrm{mg} \mathrm{PD}, \mathrm{n}(\%)\end{array}$ & $70(29.5)$ & $72(30.9)$ & 0.747 \\
\hline $\begin{array}{l}\text { Initial steroid dose of } \\
45-60 \mathrm{mg} P \mathrm{PD}, \mathrm{n}(\%)\end{array}$ & $29(12.2)$ & $39(16.7)$ & 0.165 \\
\hline Initial steroid dose of $\geq 60 \mathrm{mg}$ & $138(58.2)$ & $122(52.4)$ & 0.201 \\
\hline
\end{tabular}

PD, n (\%)

\begin{tabular}{|c|c|c|c|}
\hline \multicolumn{4}{|c|}{ Concomitant immunosuppressive treatment } \\
\hline $\begin{array}{l}\text { Steroid pulse treatment, } \\
\mathrm{n}(\%)\end{array}$ & $84(35.7)$ & $80(34.0)$ & 0.699 \\
\hline $\begin{array}{l}\text { Oral cyclophosphamide, } \\
\text { n (\%) }\end{array}$ & $20(8.5)$ & 25 (10.6) & 0.433 \\
\hline $\begin{array}{l}\text { Cyclophosphamide pulse } \\
\text { treatment, } \mathrm{n}(\%)\end{array}$ & $54(23.0)$ & $54(23.0)$ & 1.000 \\
\hline $\begin{array}{l}\text { Cumulative steroid dose, } \\
\text { mean (SD)§ }\end{array}$ & $2696.6(2123.1)$ & $2898.6(1558.8)$ & 0.240 \\
\hline Lymphopenia, n (\%)ף & $73(31.1)$ & $76(32.3)$ & 0.766 \\
\hline
\end{tabular}

${ }^{*}$ The baseline date was defined as the day on which PCP prophylaxis (prophylaxis group) or high-dose steroid (control group) was started.

tThe main reason for the use of high-dose steroids in these diseases was associated interstitial lung disease.

FIncluding Takayasu's arteritis, temporal arteritis and relapsing polychondritis. $\S$ Cumulative steroid (prednisone) dose during the previous 6 months. IDefined as $<800$ lymphocytes $/ \mathrm{mL}$.

EGPA, eosinophilic granulomatosis with polyangiitis; GPA, granulomatosis with polyangiitis; MPA, microscopic polyangiitis; $P C P$, pneumocystis pneumonia; $P D$, prednisone; PS, propensity score.

prophylaxis $(\mathrm{HR}=0.07 ; 95 \% \mathrm{CI} 0.01$ to 0.54$)$. This result was also consistent with the result of multivariable analysis including age and MPA as covariates (adjusted HR $=0.07$; 95\% CI 0.01 to 0.53$)$. PCP-related mortality in the prophylaxis group fell significantly in both univariable analysis $(\mathrm{HR}=0.07,95 \%$ profile likelihood CI 0.0005 to 0.55 ) and multivariable analysis (adjusted HR $=0.08 ; 95 \%$ profile likelihood CI 0.0006 to 0.71 ) (table 3). The HR and its significance level for other covariates are presented in online supplementary table S3. 


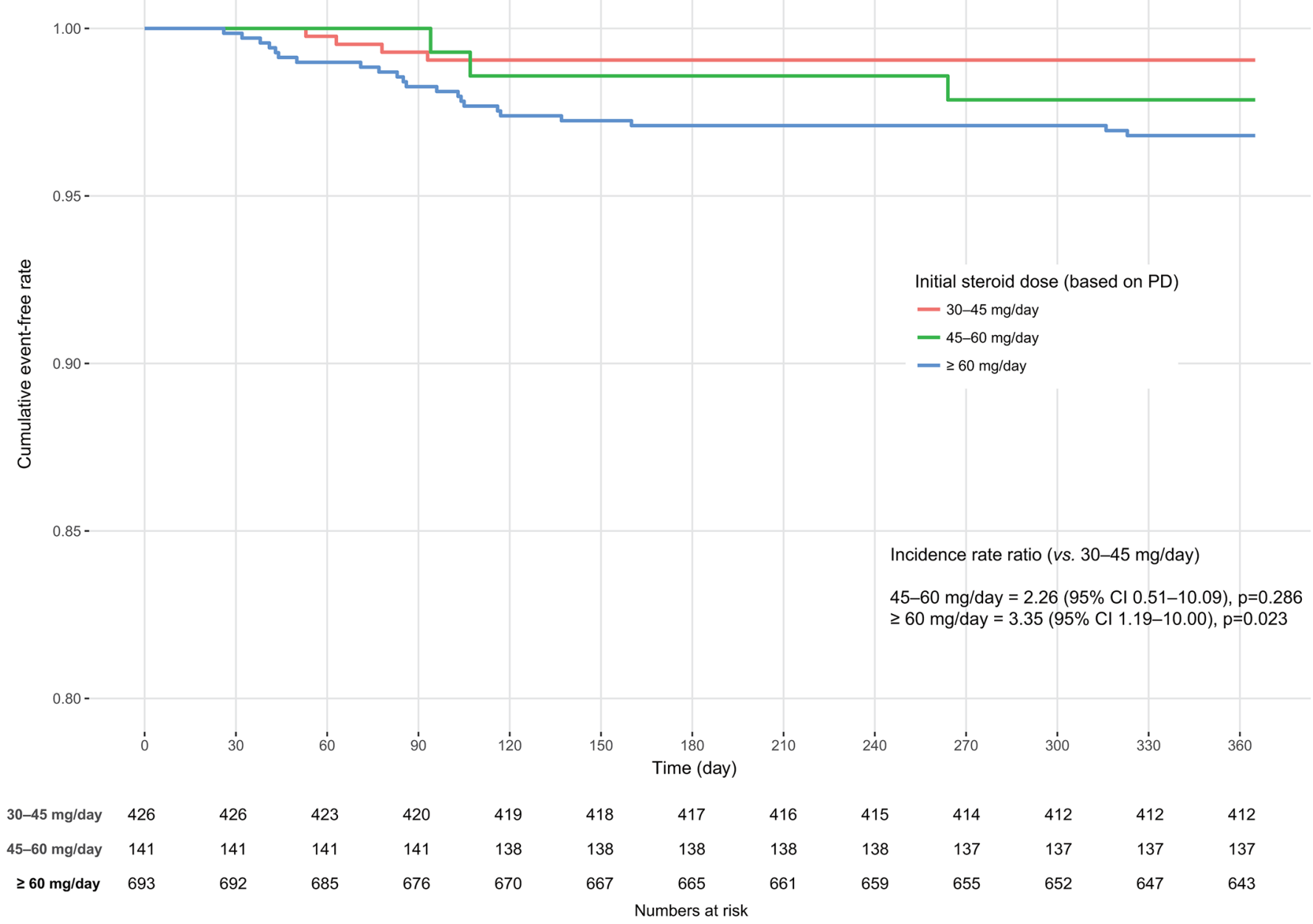

Figure 1 Kaplan-Meier curve showing pneumocystis pneumonia (PCP)-free survival according to the initial dose of steroids (30-45 mg/day prednisone, $45-60 \mathrm{mg} /$ day and $\geq 60 \mathrm{mg} /$ day) in the whole population. PD, prednisone.

Since the incidence of PCP increased according to the increase in the initial steroid dose, we next examined the efficacy of TMP-SMX prophylaxis after stratifying all treatment episodes by this factor. In the subgroup with a higher initial steroid dose $(\geq 60 \mathrm{mg} /$ day prednisone) ( $n=261)$, TMP-SMX led to a significant reduction in PCP incidence after adjusting for GPA (adjusted $\mathrm{HR}=0.05 ; 95 \%$ profile likelihood CI 0.0004 to 0.40 ). However, the effectiveness was not

Table 3 Effect of TMP-SMX prophylaxis on 1-year PCP incidence and related mortality in the propensity score-matched population $(n=470)$

\begin{tabular}{|c|c|c|c|c|}
\hline & \multicolumn{2}{|c|}{ 1-year PCP incidence } & \multicolumn{2}{|c|}{ 1-year PCP-related mortality* } \\
\hline & \multicolumn{2}{|l|}{$\begin{array}{l}\text { HR } \\
(95 \% \mathrm{Cl})\end{array}$} & \multicolumn{2}{|c|}{$\begin{array}{l}\text { HR } \\
\text { (95\% profile likelihood CI) }\end{array}$} \\
\hline & $\begin{array}{l}\text { Univariable } \\
\text { analysis }\end{array}$ & $\begin{array}{l}\text { Multivariable } \\
\text { analysist }\end{array}$ & $\begin{array}{l}\text { Univariable } \\
\text { analysis }\end{array}$ & $\begin{array}{l}\text { Multivariable } \\
\text { analysis } \neq\end{array}$ \\
\hline $\begin{array}{l}\text { TMP-SMX } \\
\text { prophylaxis }\end{array}$ & $\begin{array}{l}0.07(0.01 \text { to } \\
0.54)\end{array}$ & $\begin{array}{l}0.07 \\
(0.01 \text { to } 0.53)\end{array}$ & $\begin{array}{l}0.07(0.0005 \text { to } \\
0.55)\end{array}$ & $\begin{array}{l}0.08(0.0006 \text { to } \\
0.71)\end{array}$ \\
\hline $\begin{array}{l}\text { P value for } \\
\text { HR }\end{array}$ & 0.010 & 0.010 & 0.007 & 0.019 \\
\hline \multicolumn{5}{|c|}{$\begin{array}{l}\text { *Firth's penalised maximum likelihood was used due to complete separation of } \\
\text { outcome. } \\
\text { tIncluded age and MPA as covariates, and was also adjusted for clustering. } \\
\text { fIncluded age, GPA and MPA as covariates, and was also adjusted for clustering. } \\
\text { GPA, granulomatosis with polyangiitis; MPA, microscopic polyangiitis; PCP, } \\
\text { pneumocystis pneumonia; TMP-SMX, trimethoprim-sulfamethoxazole. }\end{array}$} \\
\hline
\end{tabular}

apparent in the subgroup receiving a lower initial steroid dose $(\mathrm{HR}=0.36 ; 95 \%$ profile likelihood CI 0.04 to 2.21$)$.

\section{Efficacy of TMP-SMX prophylaxis in the whole population}

In the whole population, the 1-year incidence of PCP tended to decrease with prophylaxis ( $\mathrm{HR}=0.17 ; 95 \% \mathrm{CI} 0.02$ to 1.22 ). MPA, higher steroid dose, concomitant cyclophosphamide pulse and baseline lymphopenia were associated with an increased incidence of PCP (see online supplementary table S4). After adjusting for these factors, the prophylaxis group showed a significantly lower incidence of PCP than control group $(\mathrm{HR}=0.06$; 95\% CI 0.004 to 0.66 ) (table 4). As in the PS-matched population, TMP-SMX significantly reduced PCP incidence only in the subgroup with a higher initial steroid dose $(n=825)$ (adjusted $\mathrm{HR}=0.02 ; 95 \%$ profile likelihood CI 0.0001 to 0.24 ).

TMP-SMX was also associated with a reduction in PCP-related mortality after adjusting for age, GPA, MPA and concomitant steroid pulse treatment (adjusted HR $=0.09$; 95\% profile likelihood CI 0.0007 to 0.76 ) (table 4).

\section{ADRs associated with prophylactic TMP-SMX}

During the 170.1 person-year duration of TMP-SMX prophylaxis, 36 ADRs (of any type) occurred in 32 patients (21.2/100 personyears; $95 \% \mathrm{CI} 14.8$ to 29.3). The most common ADRs were elevated ( $>1.5$ the upper normal range) serum alanine transaminase levels and a skin rash (3.5/100 person-years for both), followed by thrombocytopenia (1.8/100 person-years) and hyperkalaemia 
Table 4 Effect of TMP-SMX prophylaxis on 1-year PCP incidence and related mortality in the whole population $(n=1522)$

\begin{tabular}{|c|c|c|c|c|}
\hline & \multirow{2}{*}{\multicolumn{2}{|c|}{$\begin{array}{l}\text { 1-year PCP incidence } \\
\text { HR } \\
(95 \% \mathrm{Cl})\end{array}$}} & \multirow{2}{*}{\multicolumn{2}{|c|}{$\begin{array}{l}\text { 1-year PCP-related mortality* } \\
\text { HR } \\
\text { (95\% profile likelihood CI) }\end{array}$}} \\
\hline & & & & \\
\hline & $\begin{array}{l}\text { Univariable } \\
\text { analysis }\end{array}$ & $\begin{array}{l}\text { Multivariable } \\
\text { analysis } t\end{array}$ & $\begin{array}{l}\text { Univariable } \\
\text { analysis }\end{array}$ & $\begin{array}{l}\text { Multivariable } \\
\text { analysis } \neq\end{array}$ \\
\hline $\begin{array}{l}\text { TMP-SMX } \\
\text { prophylaxis }\end{array}$ & $\begin{array}{l}0.17 \text { (0.02 to } \\
1.22)\end{array}$ & $\begin{array}{l}0.06 \\
(0.004 \text { to } 0.66)\end{array}$ & $\begin{array}{l}0.21 \text { (0.002 to } \\
1.61)\end{array}$ & $\begin{array}{l}0.09(0.0007 \text { to } \\
0.76)\end{array}$ \\
\hline $\begin{array}{l}\text { P value for } \\
\text { HR }\end{array}$ & 0.078 & 0.022 & 0.165 & 0.023 \\
\hline \multicolumn{5}{|c|}{$\begin{array}{l}\text { *Firth's panelised maximum likelihood was used due to complete separation of } \\
\text { outcome. } \\
\text { tIncluded age, MPA, initial steroid dose ( } \geq 60 \mathrm{mg} / \text { day prednisone vs not), } \\
\text { concomitant cyclophosphamide pulse and baseline lymphopenia as covariates, and } \\
\text { was also adjusted for clustering. } \\
\text { fIncluded age, GPA, MPA and concomitant steroid pulse as covariates, and was also } \\
\text { adjusted for clustering. } \\
\text { GPA, granulomatosis with polyangiitis; MPA, microscopic polyangiitis; PCP, } \\
\text { pneumocystis pneumonia; TMP-SMX, trimethoprim-sulfamethoxazole. }\end{array}$} \\
\hline
\end{tabular}

(1.8/100 person-years) (table 5). There were no lupus flares during prophylaxis. In most cases, ADR severity was mild to moderate $(34 / 36,94.4 \%)$. There were only two cases of serious ADRs that led to prolonged hospitalisation (one case of pancytopenia and one case of Stevens-Johnson syndrome) (1.2/100 person-years, 95\% CI 0.1 to 4.2$)$. However, they resolved shortly after discontinuation of TMP-SMX.

\section{Risk-benefit analysis of TMP-SMX prophylaxis}

Based on the two cases of serious ADR, the number needed to harm $(\mathrm{NNH})$ was $131(55-\infty)$. By contrast, the number needed to treat (NNT) to prevent one case of PCP in the whole population was 52 (33-124). After stratification according to each underlying disease, the NNT in patients with SLE (43 (28-85)) or MPA (3 (1.6-39.4)) was lower than the NNH. The same was true for other diseases; however, the $95 \% \mathrm{CI}$ for absolute risk reduction extended

\begin{tabular}{|c|c|c|}
\hline & Number of cases* & Incidence rate $(95 \% \mathrm{Cl}) \dagger$ \\
\hline Adverse drug reactions & 34 & 20.6 (14.3 to 28.6$)$ \\
\hline Anaemia & 2 & $1.2(0.1$ to 4.2$)$ \\
\hline Leucopenia & 1 & 0.6 (0.0 to 3.3$)$ \\
\hline Thrombocytopenia & 3 & 1.8 (0.4 to 5.2$)$ \\
\hline Gl problems & 2 & 1.2 (0.1 to 4.2$)$ \\
\hline LFT abnormality & 6 & 3.5 (1.3 to 7.7$)$ \\
\hline Skin rash & 6 & 3.5 (1.3 to 7.7$)$ \\
\hline Azotaemia & 5 & 3.0 (1.0 to 7.1$)$ \\
\hline Hyperkalaemia & 3 & 1.8 (0.4 to 5.2 ) \\
\hline Others $¥$ & 6 & 3.5 (1.3 to 7.7$)$ \\
\hline $\begin{array}{l}\text { Serious adverse drug } \\
\text { reactions }\end{array}$ & 2 & $1.2(0.1$ to 4.2$)$ \\
\hline Pancytopenia & 1 & 0.6 (0.0 to 3.3$)$ \\
\hline $\begin{array}{l}\text { Stevens-Johnson } \\
\text { syndrome }\end{array}$ & 1 & $0.6(0.0$ to 3.3$)$ \\
\hline \multicolumn{3}{|c|}{$\begin{array}{l}\text { *Total observation period was } 170.1 \text { person-years for } 262 \text { cases. } \\
\text { tRate per } 100 \text { person-years. } \\
\text { fIncluding headache (1), anorexia (1), eosinophilia (1), tingling sensation (1) and } \\
\text { pruritus (2). } \\
\text { Gl, gastrointestinal; LFT, liver function test. }\end{array}$} \\
\hline
\end{tabular}

from a negative number to a positive number, making it irrelevant. Interestingly, when we stratified treatment episodes according to initial steroid dose ( $\geq 60 \mathrm{mg} /$ day prednisone vs other), the NNT for the subgroup receiving a higher steroid dose was 32 (22-54), whereas that for the subgroup receiving a lower steroid dose was $215(45-\infty)$, which is higher than the NNH for serious ADRs.

\section{Sensitivity analysis}

Because differences in the dosing regimens of TMP-SMX could have influenced its efficacy, we performed the same Cox regressions after excluding subgroups with atypical TMP-SMX dosing, including (1) twenty-three treatment episodes with a renal dose adjustment, (2) ten with a thrice weekly TMP-SMX regimen and (3) nine with more than a month's delay in prophylaxis. The result from each of these analyses was consistent with the original one (data not shown).

Since patients in the prophylaxis group discontinued TMP-SMX at various times, we analysed the data using a censoring scheme based on tapering of steroids (eg, $30 \mathrm{mg} /$ day and $15 \mathrm{mg} /$ day prednisone). The prophylactic effect of TMP-SMX was unchanged (see online supplementary figure S3). In addition, to minimise the effect of heterogeneity in the duration of prophylaxis, we also performed the same analysis using 6 and 3-month observation periods, respectively. Using these censoring schemes, the mean (SD) proportion of time that TMP-SMX was administered was significantly increased $(0.50(0.33)$ in the original analysis vs $0.70(0.32)$ and $0.86(0.25)$ in 6-month and 3 -month time frames, respectively, $\mathrm{P}<0.001$ ). However, the efficacy of prophylaxis was unaffected by the change in observation period (see online supplementary figure S4).

\section{DISCUSSION}

Systemic high-dose steroid treatment is one of the most important weapons against rheumatic diseases; however, it is a risk factor for PCP. Many studies describe an association between PCP and steroid use in patients with rheumatic disease, but few have investigated the prophylactic effects in such populations. ${ }^{16-18}$ To the best of our knowledge, this is the largest study conducted to investigate the efficacy and safety of TMP-SMX prophylaxis in patients with rheumatic diseases who received prolonged high-dose steroids. The incidence of PCP in the control group was 2.37/100 personyears, which is consistent with previous reports. ${ }^{19}$

TMP-SMX was highly effective at preventing PCP and related mortality. In contrast, compared with that reported in other studies of HIV-positive patients, TMP-SMX showed a lower incidence of ADRs. ${ }^{20}$ Recent meta-analyses on the efficacy of PCP prophylaxis in patients with haematologic malignancy or post-transplantation suggest that TMP-SMX should be considered when the NNT is balanced against the NNH for severe ADRs. ${ }^{21} 22$ Overall, the NNT herein was 52, whereas that for severe ADRs was 131, illustrating that the benefit of TMP-SMX prophylaxis was greater than the risk of potential harm to the patient. Interestingly, in the subgroup that received a higher initial steroid dose, the NNT was even lower. This demonstrates that, in patients receiving $\geq 60 \mathrm{mg} /$ day prednisone, the benefits of TMP-SMX prophylaxis outweigh the risks. This result suggests that initial steroid dose may identify patients who would derive maximum benefit from TMP-SMX prophylaxis.

The optimal time to stop PCP prophylaxis in non-HIV patients receiving high-dose steroids remains unclear. Expert opinion suggests that prophylaxis should be continued until the CD4 T cell count rises above $200 / \mathrm{mm}^{3}$ for 6 consecutive months. ${ }^{23}$ However, the correlation between this factor and the risk for PCP is less clear in patients without HIV. ${ }^{24}$ In that context, it is noteworthy that most PCP cases $(90.0 \%)$ in the present study occurred when 
a patient received $\geq 15 \mathrm{mg} /$ day prednisone or equivalent, which is in line with the findings of previous studies. ${ }^{13} 182425$ This suggests that tapering the dose of steroid down to $<15 \mathrm{mg}$ /day might be a relevant point at which to consider stopping prophylaxis. In agreement with previous reports, we found that PCP showed a significant association with concomitant cyclophosphamide, lymphopenia and old age, and at least one of these risk factors was present in all instances of PCP in patients receiving $<15 \mathrm{mg} /$ day prednisone. ${ }^{132326}$ However, because of the small number of PCP cases, it should be precautious to define relevant time point of stopping prophylaxis with this result alone.

This study has some limitations. First, the baseline characteristics of the prophylaxis and non-prophylaxis groups were not fully balanced, a limitation inherent to observational studies. To overcome this limitation, primary analysis was performed based on PS-matching population; however, unmeasured confounders such as physician's preference cannot be completely balanced without randomisation. Second, the number of PCP cases in this study was rather small so we could not perform a precise risk-benefit assessment for some rheumatic diseases. In addition, because this was not a randomised controlled study, we could not compare the prevalence of adverse events between the two groups; therefore, the $\mathrm{NNH}$ was based on the ADR from the prophylaxis group alone.

In conclusion, we show here the benefit of TMP-SMX as primary prophylaxis for PCP in patients with rheumatic diseases who were treated with prolonged high-dose steroids; this was particularly true for patients receiving an initial steroid dose $\geq 60 \mathrm{mg} /$ day prednisone or equivalent. Although the results should be confirmed in a future randomised study, the data may impact the use of PCP prophylaxis for patients with rheumatic diseases.

Contributors EBL had full access to all of the data in the study and takes responsibility for the integrity of the data and the accuracy of the data analysis. Study concept and design: EBL, JRC, SK and JWP. Acquisition, analysis or interpretation of data: JWP, JRC, JM, YWS and EBL. Drafting of the manuscript: EBL, JRC and JWP. Critical revision of the manuscript for important intellectual content: JWP, JRC, JM, YWS, SK and EBL. Statistical analysis: EBL, JRC and JWP.

Funding This research was partly supported by Basic Science Research Program through the National Research Foundation of Korea (NRF) funded by the Ministry of Education (2016R1D1A1A02937044).

Competing interests EBL has acted as a consultant to Pfizer, and received research grants from Green Cross Corp and Hanmi Pharm Company. The other authors declare no conflicts of interest.

Patient consent Informed consents were waived based on the retrospective nature of the study.

Ethics approval The study was approved by the Institutional Review Board of the Seoul National University Hospital (IRB 1508-050-694) and was conducted in accordance with the principles of the Declaration of Helsinki and Good Clinical Practice guidelines.

Provenance and peer review Not commissioned; externally peer reviewed.

Open Access This is an Open Access article distributed in accordance with the Creative Commons Attribution Non Commercial (CC BY-NC 4.0) license, which permits others to distribute, remix, adapt, build upon this work non-commercially, and license their derivative works on different terms, provided the original work is properly cited and the use is non-commercial. See: http://creativecommons.org/ licenses/by-nc/4.0/

(c) Article author(s) (or their employer(s) unless otherwise stated in the text of the article) 2018. All rights reserved. No commercial use is permitted unless otherwise expressly granted.

\section{REFERENCES}

1 Thomas CF, Limper AH. Pneumocystis pneumonia. N Engl J Med 2004;350:2487-98.

2 Morris A, Lundgren JD, Masur H, et al. Current epidemiology of Pneumocystis pneumonia. Emerg Infect Dis 2004;10:1713-20.

3 Mansharamani NG, Garland R, Delaney D, et al. Management and outcome patterns for adult Pneumocystis carinii pneumonia, 1985 to 1995: comparison of HIVassociated cases to other immunocompromised states. Chest 2000;118:704-11.

4 Yale SH, Limper AH. Pneumocystis carinii pneumonia in patients without acquired immunodeficiency syndrome: associated illness and prior corticosteroid therapy. Mayo Clin Proc 1996;71:5-13.

5 Sepkowitz KA. Opportunistic infections in patients with and patients without Acquired Immunodeficiency Syndrome. Clin Infect Dis 2002;34:1098-107.

6 Maeda T, Babazono A, Nishi T, et al. Quantification of the effect of chemotherapy and steroids on risk of Pneumocystis jiroveci among hospitalized patients with adult T-cell leukaemia. Br J Haematol 2015;168:501-6.

7 Martin SI, Fishman JA. Pneumocystis pneumonia in solid organ transplantation. Am J Transplant 2013;13(Suppl 4):272-9.

8 Limper AH, Knox KS, Sarosi GA, et al. An official american thoracic society statement: Treatment of fungal infections in adult pulmonary and critical care patients. Am J Respir Crit Care Med 2011;183:96-128.

9 Godeau B, Coutant-Perronne V, Le Thi Huong D, et al. Pneumocystis carinii pneumonia in the course of connective tissue disease: report of 34 cases. J Rheumatol 1994:21:246-51.

10 Cettomai D, Gelber AC, Christopher-Stine L. A survey of rheumatologists' practice for prescribing pneumocystis prophylaxis. J Rheumatol 2010;37:792-9.

11 Buttgereit F, da Silva JA, Boers M, et al. Standardised nomenclature for glucocorticoid dosages and glucocorticoid treatment regimens: current questions and tentative answers in rheumatology. Ann Rheum Dis 2002;61:718-22.

12 Eitner F, Hauser IA, Rettkowski 0, et al. Risk factors for Pneumocystis jiroveci pneumonia (PCP) in renal transplant recipients. Nephrol Dial Transplant 2011;26:2013-7.

13 Lertnawapan R, Totemchokchyakarn K, Nantiruj K, et al. Risk factors of Pneumocystis jeroveci pneumonia in patients with systemic lupus erythematosus. Rheumatol Int 2009:29:491-6.

14 Edwards IR, Aronson JK. Adverse drug reactions: definitions, diagnosis, and management. Lancet 2000;356:1255-9.

15 Heinze G, Schemper M. A solution to the problem of separation in logistic regression. Stat Med 2002:21:2409-19.

16 Vananuvat P, Suwannalai P, Sungkanuparph S, et al. Primary prophylaxis for Pneumocystis jirovecii pneumonia in patients with connective tissue diseases. Semin Arthritis Rheum 2011:41:497-502.

17 Ogawa J, Harigai M, Nagasaka K, et al. Prediction of and prophylaxis against Pneumocystis pneumonia in patients with connective tissue diseases undergoing medium- or high-dose corticosteroid therapy. Mod Rheumatol 2005;15:91-6.

18 Chew LC, Maceda-Galang LM, Tan YK, et al. Pneumocystis jirovecii pneumonia in patients with autoimmune disease on high-dose glucocorticoid. J Clin Rheumatol 2015:21:72-5

19 Roux A, Gonzalez F, Roux M, et al. Update on pulmonary Pneumocystis jirovecii infection in non-HIV patients. Med Mal Infect 2014;44:185-98.

20 Rodriguez M, Fishman JA. Prevention of infection due to Pneumocystis spp. in human immunodeficiency virus-negative immunocompromised patients. Clin Microbiol Rev 2004;17:770-82.

21 Green H, Paul M, Vidal L, et al. Prophylaxis of Pneumocystis pneumonia in immunocompromised non-HIV-infected patients: systematic review and meta-analysis of randomized controlled trials. Mayo Clin Proc 2007;82:1052-9.

22 Stern A, Green H, Paul M, et al. Prophylaxis for Pneumocystis pneumonia (PCP) in non-HIV immunocompromised patients. The Cochrane database of systematic reviews 2014;01:CD005590.

23 Suryaprasad A, Stone JH. When is it safe to stop Pneumocystis jiroveci pneumonia prophylaxis? Insights from three cases complicating autoimmune diseases. Arthritis Rheum 2008:59:1034-9.

24 Overgaard UM, Helweg-Larsen J. Pneumocystis jiroveci pneumonia (PCP) in HIV-1negative patients: a retrospective study 2002-2004. Scand I Infect Dis 2007;39(67):589-95.

25 Roblot F, Le Moal G, Kauffmann-Lacroix C, et al. Pneumocystis jirovecii pneumonia in HIV-negative patients: a prospective study with focus on immunosuppressive drugs and markers of immune impairment. Scand I Infect Dis 2014;46:210-4.

26 Teichtahl AJ, Morrisroe K, Ciciriello S, et al. Pneumocystis jirovecci pneumonia in connective tissue diseases: Comparison with other immunocompromised patients. Semin Arthritis Rheum 2015:45:86-90. 